\title{
APLICAÇÃO PRÁTICA NOS CURSOS DE DIREITO DOS MEIOS ALTERNATIVOS DE SOLUÇÃO DE CONFLITOS (CONCILIAÇÃO, MEDIAÇÃO E ARBITRAGEM) ${ }^{1}$
}

\section{Eduardo Peruffo e Silva ${ }^{2}$}

Resumo: Verifica-se, na atualidade, uma sobrecarga do Poder Judiciário brasileiro, em especial no que tange a processos relacionados a direitos que podem ser solucionados sem a necessidade da intervenção estatal, os chamados direitos disponíveis. Somado a isso, está o despreparo dos aplicadores do direito para lidar com a possibilidade de composição de litígios, uma vez que as faculdades de direito tem um enfoque muito maior na prática do litígio do que na formulação de acordos. Busca o presente trabalho, portanto, apresentar e explicar os meios de solução de conflitos existentes no Direito brasileiro, bem como apresentar abordagens práticas para que os professores tenham melhores e mais eficazes mecanismos de ensino do tema, para uma melhor prática processual.

Palavras-Chave: Conciliação. Mediação. Arbitragem. Meios de solução de conflitos.

1 Artigo inicialmente apresentado como Trabalho de Conclusão de Curso em Pós-Graduação de Docência do Ensino Superior da Faculdade Pitágoras, com supervisão da Profa. MsC Márcia Proença.

2 Pós-Graduado em Docência do Ensino Superior pela Faculdade Pitágoras. Pós-graduado em Direito Constitucional pela Faculdade de Direito Damásio de Jesus. Residente Judicial na $1^{\text {a }}$ Vara Criminal da Comarca de Palhoça. Juiz Leigo no Juizado Especial Cível do Norte da Ilha (Trindade). E-mail: peruffo_peruffo@hotmail. com 


\section{INTRODUÇÃO}

É sabido que no Brasil, de acordo com o art. 5, XXXV da Constituição Federal, nenhuma lesão ou mesmo sua ameaça será excluída da apreciação do Poder Judiciário, sendo este dispositivo legal considerado Direito Fundamental pelos Tribunais Superiores, em especial pelo Supremo Tribunal Federal.

Com esta determinação constitucional, e em especial após a Lei 9.099/95 (Lei dos Juizados Especiais Estaduais) e seus instrumentos de facilitação de acesso à justiça, houve uma avalanche processual, na qual o aparato estatal não se viu preparado para dar solução rápida e eficaz às inúmeras demandas que surgiram.

Com isso, houve a necessidade de se criarem mecanismos para que se pudessem solucionar de outros meios os conflitos de interesses levados ao Judiciário, tais como a conciliação, mediação e arbitragem.

Contudo, verifica-se que os currículos das faculdades de Direito do Brasil pouco exploram tal disciplina, especialmente pela própria cultura do litígio em que se vive o Direito brasileiro.

Assim, surge a necessidade de se explorar melhor os conhecimentos de tais soluções de conflitos, bem como uma aplicação prática dos mesmos para melhor preparação dos operadores do Direito.

\subsection{Conflito}

Mas afinal, o que é conflito? Embora muito se fale, nos livros de direito, sobre conflito, pouco se mostra qual seu real significado. Tentando solucionar tal lacuna, André Gomma de Azevedo explica:

O conflito pode ser definido como um processo ou estado em que duas ou mais pessoas divergem em razão de metas, interesses ou objetivos individuais percebidos como mutuamente incompatí- 
veis. Um conflito pode ser experimentado como uma simples discordância ou oposição e como uma percepção de diferença dos outros ou uma competição ou incompatibilidade com outros. (...)

Em termos coloquiais, conflito refere-se a um desentendimento - a expressão ou manifestação de um estado de incompatibilidade (AZEVEDO, 2012, p. 110).

E ainda segue com as teorias do grande Morton Deutsch:

Sob a perspectiva de Deutsch, ao se presumir que o conflito consiste em um fenômeno negativo nas relações humanas, tende-se a proceder a uma análise de culpabilidade seguida de uma relação marcantemente competitiva. Naturalmente, a opção pela adoção de uma conduta de cooperação ou competição entre as pessoas e grupo proporciona consequências significativamente distintas. A competição tende a induzir participantes a disputar o que se percebe como recursos limitados fazendo-se uso de condutas claramente adversariais, belicosas, polarizadoras e que proporciona ao menos um perdedor.

Por outro lado, ao se perceber o conflito como algo positivo, ou ao menos potencialmente positivo, tem-se que o mecanismo de luta ou fuga tende a não ser desencadeado ante a ausência de percepção de ameaça. Essa percepção não ameaçadora, por sua vez, proporciona reações (e.g., equilíbrio, serenidade, compreensão, simpatia, consciência verbal) mais propensas a facilitar que processos produtivos de resolução de disputas sejam desencadeados (AZEVEDO, 2012, P. 112).

Assim, verifica-se que o conflito pode ser analisado por duas óticas distintas, uma positiva e outra negativa, segundo Deutsch. E essa análise pode ser fundamental para que os conflitos trazidos ao judiciário não se perpetrem no tempo, mesmo após uma sentença definitiva (por exemplo, nos casos 
de direito de família, em que, em sua maioria, não se busca o ganho material, mas sim o ganho afetivo).

Contudo, talvez (infelizmente) este seja um conceito distante de conflito aos operadores de direito, que preferem seu significado jurídico, conforme demonstra Candido Rangel Dinamarco:

O conceito de conflito não é muito claro em doutrina. A mais abalizada tentativa de defini-lo foi a que o envolveu na ideia de lide, apontada como conflito de interesses qualificado por uma pretensão resistida (Carnelutti). $\mathrm{O}$ conflito, elemento substancial da lide, seria representado pela incidência de interesses de dois ou mais sujeitos sobre o mesmo bem, sendo este insuficiente para satisfazer a ambos, ou a todos esses interesses. A exteriorização do conflito, ou seu elemento formal, seria a tensão entre a exigência externada por um sujeito (pretensão) e a resistência oposta pelo outro. Essa construção, além de exageradamente litigada a relações de direito privado, dá destaque a algo que socialmente é quase indiferente, ou seja, ao conflito conforme definido pelo autor. Na vida social o que incomoda e aflige não é a teórica incidência de interesses sobre o bem, mas justamente as exigências não satisfeitas (DINAMARCO, 2004., p. 116).

\subsection{Jurisdição}

Antes de vermos quais são os meios alternativos de solução de conflitos, entendemos necessário traçar um ponto fundamental que dá início a toda a ideia de conflito: a jurisdição. Em sua mais simples conotação, pode-se dizer que a jurisdição é um poder estatal, decorrente da soberania exercida por um país dentro de seu território de solucionar conflitos. É o poder que se investe o Estado-Juiz em dirimir conflitos. Sobre o tema, didaticamente leciona Candido Rangel Dinamarco: 
Assumindo que o sistema processual é impulsionado por uma série de escopos e que o Estado chama a si a atribuição de propiciar a consecução destes, uma das funções estatais é de realizar os escopos do processo. Tal é a jurisdição, função exercida pelo Estado através de agentes adequados (os juízes), com vista à solução imperativas de conflitos interindividuais ou supra-individuais e aos demais escopos do sistema processual. Entre esses escopos está o de atuação do direito material, tradicionalmente apontado como fator apto a dar à jurisdição uma feição própria e diferenciá-la conceitualmente das demais funções estatais - pois nenhuma outra é exercida com o objetivo de dar efetividade ao direito material em casos concretos. Conceitua-se jurisdição, a partir dessas premissas, como função do Estado, destinada à solução imperativa de conflitos e exercida mediante a atuação da vontade do direito em casos concretos (DINAMARCO, 2004, p. 298).

Ainda sobre o tema, assim insere Luiz Rodrigues Wambier e Eduardo Talamini:

A jurisdição é, portanto, no âmbito do processo civil, a função que consiste primordialmente em resolver os conflitos que a ela sejam apresentados pelas pessoas, naturais ou jurídicas (e também pelos entes despersonalizados, tais como o espólio, a massa falida e o condomínio), em lugar dos interessados, por meio da aplicação de uma solução prevista pelo sistema jurídico (WAMBIER, 2013, p. 95).

Considerando, portanto, que a jurisdição (em sentido de solução de conflitos de interesse) é uma atividade privativamente estatal, como se justifica a possibilidade de particulares ou terceiros solucionarem tal conflito?

Ocorre que a jurisdição só existe em função da lei, e esta como consequência da soberania. A solução dos conflitos, como conceituou Dinamarco, é a atuação da vontade do direito nos 
casos concretos. Assim, se analisarmos a letra do art. 125, IV do Código de Processo Civil (CPC), verifica-se que é um dever do juiz a tentativa, a qualquer tempo, de conciliar as partes. Partindo dessa singela ideia, pode-se inferir que o Estado não tem o poder de retirar completamente o poder dos conflitantes de solucionar seu conflito da forma que melhor lhes aprouver. O que deve fazer é, contudo, ordenar esta solução, para que não se exceda direitos que lhe são devidos.

Passada esta fase, necessário se faz tecer alguns comentários sobre os meios alternativos de solução de conflito, também chamados de "Equivalentes Jurisdicionais".

\subsection{Equivalentes jurisdicionais}

Interessante conceituação sobre equivalentes jurisdicionais traz Fredie Didier Jr.:

Equivalentes jurisdicionais são as formas não jurisdicionais de solução de conflitos. São chamadas de equivalentes exatamente porque, não sendo jurisdição, funcionam como técnica de tutela de direitos, resolvendo conflitos ou certificando situações jurídicas (DIDIER JUNIOR, 2012, p. 104).

Todas essas formas de solução de conflitos não são definitivas, pois podem ser submetidas ao controle jurisdicional.

Importante tratamento traz Dinamarco sobre o tema:

A crescente valorização e emprego de meios não judiciais de pacificação e condução à ordem jurídica justa, ditos meios alternativos, reforça a ideia da equivalência entre eles e a atividade estatal chamada jurisdição (DINAMARCO, 2004, p. 106).

Ainda, faz o autor uma didática distinção entre os meios de composição de conflitos, distinguindo-os entre heterocomposição (quando um terceiro - que não o juiz - decide a lide), e autocomposição (quando as próprias partes decidem o conflito): 
Uma ordem de soluções apontadas como socialmente convenientes, além de juridicamente legítimas, é aquela integrada por atividades reunidas nos conceitos de autocomposição e no de heterocomposição (Niceto Acalá-Zamora y Castillo). (...)

Existe autocomposição quando os próprios sujeitos envolvidos no conflito, ou um deles unilateralmente, encontra caminho apto à pacificação. (...)

Como meio alternativo de heterocomposição avulta o juízo arbitral, a arbitragem, que consiste no julgamento do litígio por pessoa escolhida consensualmente pelas partes (o árbitro), mediante trâmites bastante simplificados e menor apego a parâmetros legais rígidos (DINAMARCO, 2004, p. 120).

\subsection{Autotuela}

A autotutela é o meio de imposição da vontade do mais forte, e é uma solução proibida no direito brasileiro, podendo, inclusive, configurar crime de "Exercício Arbitrário das Próprias Razões”, previsto no art. 345 do Código Penal (CP). Assim ensina Fredie Didier Jr. (2012, p. 105): "Trata-se de solução do conflito de interesses que se dá pela imposição da vontade de um deles, com o sacrifício do interesse do outro. Solução egoísta e parcial do litígio. O juiz da causa é uma das partes (...)".

Trata-se de solução vedada, como regra, nos ordenamentos jurídicos civilizados.

\subsection{Mediação}

Mediação é uma forma de solução de conflitos em que um terceiro tenta conduzir às partes litigantes a uma solução que melhor lhes aprouver. Trata-se de um profissional que auxilia as partes a encontrarem uma solução que melhor se ajuste aos interesses de cada um, dando fim ao litígio. Assim leciona Didier Jr.: 
A mediação é uma técnica não estatal de solução de conflitos, pela qual um terceiro se coloca entre os contentores e tenta conduzi-los à solução autocomposta. O mediador é um profissional qualificado que tenta fazer com que os próprios litigantes descubram as causas do problema e tentem removê-las. Trata-se de técnica para catalisar a autocomposição (DIDIER JUNIOR, 2012, p. 106).

A mediação talvez seja uma das mais interessantes formas de solução de conflitos, pois trata o conflito como um problema a ser superado não apenas naquele "problema” específico, mas sim como análise geral do contexto conflituoso. Bem anota Rafael Mendonça:

A base do sistema utilizado na Mediação é o tratamento das pessoas como seres humanos únicos, que devem esclarecer suas dificuldades em uma inter-relação (afetiva, profissional, etc.), com desejos de aprimorá-la. Nesse sistema os participantes têm o controle das etapas do processo que serão trabalhadas, pois se busca um diálogo que os faça compreender o que é que, nelas, as fez levar ao conflito (como eclosão de insatisfações), para que dessa forma criem responsavelmente as soluções para a convivência satisfatória futura, não sendo assim escravos de soluções impostas (MENDONÇA, 2006, p. 104).

E segue, ainda, falando da necessidade dos conhecimentos multidisciplinares que deve o mediador ter:

Como a Mediação de Conflitos visa à solução, entendimento ou possibilidade dos sujeitos conviverem com os conflitos, o mediado necessita partilhar de um conhecimento transdisciplinar. Um hiperespecialista em determinado conteúdo é inútil diante do complexo psíquico-físico dos indivíduos mediados. Estaria muito limitado para aquele que expressa, pois o que é dito pelos mediados não são somente aspectos da disciplina do Direito, da Medicina, da Psicanálise etc., são, 
como visto, o pseudônimo da condição humana. Agir uni-disciplinarmente seria como que se em determinados momentos os mediados fizessem mímicas para o mediador, tentando lhe dizer algo ("Nos ajude nisso! Aqui, veja!"), mas ele não conseguisse compreender, pois só vem a "entender" um tipo de conhecimento, linguagem (MENDONÇA, 2006, p. 106).

\subsection{Conciliação}

Na conciliação, que também é forma de solução de conflitos entre as partes, o conciliador, terceiro que se coloca entre as partes, auxilia , podendo inclusive fazer sugestões para que as partes cheguem num consenso. Talvez a maior diferença com a mediação seja que o conciliador possa interferir diretamente no conflito, não apenas mediando as partes, isto é, servindo de mero interventor, mas fazendo sugestões aplicáveis ao caso concreto para que os litigantes, querendo, acolham tais sugestões.

Assim delimita o Conselho Nacional de Justiça (CNJ) em seu programa "Semana Nacional da Conciliação":

A Conciliação jamais gera qualquer tipo de imposição: os conciliadores podem fazer sugestões ou até mesmo propor soluções para o conflito, mas as partes são livres para aceitar ou não as propostas, uma vez que cabe somente a elas a solução do referido conflito. Para isso, vários conciliadores estão sendo devidamente capacitados pelos tribunais, visando à perfeita realização dessa atividade (CONSELHO NACIONAL DE JUSTIÇA, 2013).

\subsection{Arbitragem}

É técnica heterocompositiva de conflitos, vez que os litigantes buscam um terceiro, de sua confiança, para uma solução amigável e imparcial. O terceiro (árbitro), impõe a sua decisão às partes que o escolheram. 


\title{
Assim ensina José Miguel Garcia Medina:
}

\begin{abstract}
A arbitragem, também denominada 'jurisdição privada', consiste num instrumento de composição de controvérsias fundada na autonomia da vontade das partes. A noção de que todo conflito de interesses deva ser solucionado pela atuação de órgãos jurisdicionais sofre uma atenuação pela aplicação da arbitragem (MEDINA, 2012, p. 341).
\end{abstract}

Interessante resaltar que a arbitragem tem um regramento muito mais sutil que o próprio formalismo processual, bem como têm-se soluções muito mais ágeis, fazendo com que litígios envolvendo grandes empresas acabem por serem solucionados pela arbitragem.

Por outro lado, o elevado custo do procedimento arbitral afasta os menores litigantes desta forma de solução de conflitos.

\subsection{Aplicação prática}

Verificados os conceitos iniciais, surge então a necessidade de explorarmos as formas metodológicas das quais os professores de Direito possam trabalhar tais meios de solução.

Embora as faculdades de Direito tenham um currículo extremamente voltado à teoria, entendo que a melhor forma de se aprender tal conteúdo é a prática, em especial por serem elementos que são exercidos pelos operadores de direito de forma diária.

Sobre a formação dos mediadores, critica de forma bastante lúcida Luís Alberto Warat, em sua obra "O Ofício do Mediador", questionando "Como se forma um mediador?":

Formulo essa pergunta porque creio que as escolas de mediação, em sua grande maioria, estão fracassando como formadoras de mediadores. Elas se ocupam em proporcionar técnicas e rituais, um guia de formalidades, um receituário de boas recomendações, um planejamento para conseguir que as partes possam chegar a um acordo. Formam conciliadores, negociadores, não mediadores. 
A grande maioria das escolas de mediação preocupam-se em produzir um profissional, introduzindo técnicas periféricas e estereotipadas de comunicação. Alguns falam em planejar o jogo, como se fosse uma partida de xadrez, que deve ser preparada para que os rivais possas propor-se tablas (WARAT, 2001, p. 41).

Ademais, retomando a ideia já apresentada sobre a interdisciplinaridade necessária para a formação de um mediador, traz Marina Soares Vital Borges, explanando Vygotsky:

Um dos conceitos mais importantes desenvolvidos por Vygotsky é a Zona de Desenvolvimento Proximal - ZPD. Segundo esse autor o desenvolvimento pleno do ser humano depende do aprendizado que realiza um determinado grupo cultural, a partir da interação com os outros indivíduos da sua espécie.

A atividade coletiva e o aprendizado social permitem que se ultrapasse os limites do desenvolvimento real, até se alcançar a plena maturidade, o que explica também como os conceitos abstratos podem ser adquiridos pela experiência concreta do cotidiano (BORGES, 2006, p. 145).

E segue:

Vygotsky, inspirado nos princípios do materialismo dialético, criou a abordagem sócio-interacionista, sendo de grande proveito para o ensino do Direito. Segundo ele, organismo e meio exercem influência recíproca, portanto o biológico e social não estão dissociados, sendo o indivíduo resultado de uma interação dialética entre o ser humano e o meio cultural em que se insere. (BORGES, 2006, p. 145).

Por serem exercitados no dia-a-dia forense, emerge a necessidade de se propiciar, em sala de aula, um ambiente propício a, controladamente e sob orientação, fazer com que os alunos experimentem tais meios de solução de conflito. 
Entre as diversas formas de práticas trazidas por Marcos T. Masetto (Docência Universitária - Repensando a Aula) podemos verificar que, talvez as que melhor trariam resultados ao ensino dos meios alternativos de solução de conflitos, seria um conjunto composto por aula expositiva, painel integrado, projeto e situação real prática.

Trata-se, portanto, de um sequenciamento de aulas (o que faz com que a Faculdade venha a disponibilizar uma carga horária mais ampliada para o tema, possivelmente, e já sugerindo, uma disciplina específica para o desenvolvimento das alternativas de solução conflituosa), e não apenas uma única aula para desenvolver toda a temática, como, infelizmente, hoje ocorre, fazendo com que os profissionais pouco saibam atuar na vida real, conforme coloca Vanderlei Deolindo:

Os acadêmicos, em regra, são talhados ao apego técnico-processual, com no mínimo quatro cadeiras/ matérias de Processo Civil, mais três de Processo Penal, isso quando ainda não são precedidas de outras introdutórias às respectivas áreas processuais. São rara as faculdades que desenvolvem matérias voltadas para o desenvolvimento de técnicas de conciliação e mediação, passando por arbitragem, que também se constitui numa importante via alternativa de resolução de conflitos.

Essa cultura adversarial se projeta para o âmbito profissional dos futuros advogados, promotores e juízes (DEOLINDO, 2012, p. 84).

Inicialmente, sobre a aula expositiva, bem ensina Marcos T. Masetto:

A aula expositiva é uma das técnicas mais usadas por nós professores. Será que num paradigma que valoriza a aprendizagem essa técnica ainda tem lugar? Alguns pensam que não, que ela estaria abolida. No meu entender, não se trata disso; mas, 
sim de se usar a aula expositiva como uma técnica, isto é quando ela for adequada aos objetivos que temos. Isto quer dizer que ela cabe, por exemplo, no início de um assunto para motivar os alunos a estudá-lo ou para apresentar um panorama geral do tema que será estudado posteriormente; ou como síntese de um estudo feito individual ou coletivamente, ao final dos trabalhos. Sempre usando de 20 a 30 minutos (não mais do que isso), pois é um tempo no qual conseguimos manter a atenção dos alunos, e assim mesmo com alguns recursos adicionais, como por exemplo: usar slides, vídeos, retroprojetor, apresentar casos, chamar atenção pra notícias recentes que tenham a ver com o que estamos falando, provocar o diálogo com os alunos, fazer perguntas, solicitar a participação dos alunos, por vezes convidar algum professor colega nosso da mesma Universidade para discutir o assunto com os alunos e assim por diante.

Dentro do paradigma que privilegia a aprendizagem, transmitir informações através da técnica da aula expositiva não é aconselhável, uma vez que buscar informação e trabalhar com ela é muito mais importante que ouvir as informações já organizadas, absorvê-las e depois, reproduzi-las (MESETTO, 2013).

Assim, pode-se perceber que a aula expositiva é uma excelente maneira (técnica) para introdução do conteúdo, mormente apresentando o conteúdo de forma breve e direta, objetivamente para uma visão global dos alunos sobre o assunto, para que surjam dúvidas e questionamentos a serem supridos por meio de uma pesquisa mais aprofundada. No caso, sugerimos o desenvolvimento de Painel Integrado, nos moldes apresentados por Masetto:

Painel integrado é uma técnica muito interessante e incentiva a uma grande participação por parte dos alunos. É mais apropriada para aprofundamento de um assunto e desenvolvimento de habilidades, 
como trabalhar em grupo, e desenvolvimento de atitudes de responsabilidade e crítica.

Divide-se a turma em grupos de 5 participantes e para cada grupo dá-se um tema, uma pergunta, ou um artigo, ou um capítulo de livro diferentes que deverão ser lidos individualmente antes da aula e coletivamente trabalhados no primeiro tempo da aula. Este primeiro grupo recebe uma tarefa a realizar, todos os participantes deverão ter mãos uma cópia do relatório final e distribuírem-se um número de 1 a 5 .

No segundo tempo, organizam-se novos grupos, agora agrupados pelos números 1, 2, 3, 4, 5 e para este novo grupo, nova atividade com característica de intercâmbio de informações entre eles (uma vez que cada um provem de um grupo diferente), integração dos conhecimentos produzidos e novo resultado esperado.

Por fim, o professor que esteve presente em um dos grupos do segundo momento, fará os comentários que julgar pertinentes a partir de tudo o que ouviu (MESETTO, 2013.).

Desta feita, sugerimos dividir a classe em 05 grupos com a seguinte temática para cada grupo: a) Conflitos; b) Jurisdição; c) Conceitos gerais de equivalentes jurisdicionais; d) Conciliação e Arbitragem; e) Mediação. Sequencialmente, aplicam-se as técnicas apresentadas por Masetto.

Por fim, interessante a possibilidade de desenvolvimento de um projeto com os resultados obtidos nas fases anteriores.

Projetos, sem dúvida, uma das mais completas e envolventes atividades pedagógicas coletivas. Elaboração de um projeto sempre está relacionada a uma situação profissional, a uma situação real. O grupo de alunos poderá identificar uma situação problemática, descrevê-la, levantar perguntas, fazer o diagnóstico do problema, levantar aspectos 
teóricos que sirvam de fundamentação para se compreender adequadamente aquela situação, indicação dos procedimentos a serem realizados, implementá-los, buscar solução para as questões, enfim resolver o projeto proposto.

Trabalhar com projetos é uma forma muito especial de se desenvolver tanto o ensino com pesquisa, como se experimentar uma situação de uma equipe de trabalho profissional que se reúne para desenvolver um projeto em uma firma ou em uma empresa ou em uma instituição. Tais situações exigem equipe, exigem o coletivo, exigem saber trabalhar em grupo, partilhar ideias e sugestões, respeitar ideias dos outros, colaborar, por vezes, desprender-se de suas próprias ideias em prol de uma proposta melhor (MESETTO, 2013).

Pensamos que o desenvolvimento dos projetos pode estar aliado a uma nova e importante ferramenta do Direito moderno, qual seja, o processo eletrônico.

Com o processo totalmente virtual, mais facilitado é o acesso a todas as pessoas em visualizar todos os atos de um processo real. Isso se dá com as mais diversas ferramentas tecnológicas desenvolvidas pelos Tribunais, tais como Projudi (vinculado ao CNJ), Processo Judicial Eletrônico (PJE), e o Sistema de Automação da Justiça (SAJ).

Com tais sistemas, em qualquer lugar do mundo, com acesso à internet, é possível acompanhar, em tempo real, a movimentação de um processo judicial.

Assim, ao transferirmos esta ferramenta à sala de aula, e rememorando que os processos são públicos, podemos utilizá-la para desenvolvimento dos projetos com os alunos.

Interessante seria fazer com que estes pesquisem um determinado processo no acervo virtual e dele "tomem conta". Com isso, podem ler as peças processuais existentes, e entender os conflitos ali postos. 
A partir disso, os grupos passam a ter personagens (conciliador, mediador, árbitro, advogados, partes) e com isso fazer verdadeiras sessões de soluções alternativas de conflito.

Desta feita, a prática está posta. Tal projeto pode se repetir por várias vezes, com diferentes integrantes, vez que o acervo judicial é gigantesco, conforme se vê do último relatório da Justiça Estadual, realizado pelo $\mathrm{CNJ}$ :

No decorrer de 2011, tramitaram na Justiça Estadual cerca de 70 milhões de processos, 2,2\% a mais que no ano anterior. Desse volume processual, $73 \%$ (51,7 milhões) já se encontravam pendentes desde o término do ano anterior, o que demonstra que a maior dificuldade do Poder Judiciário nos estados está na liquidação de seu estoque, pois, de forma geral, a Justiça Estadual tem sido capaz de baixar os processos em quantitativo equivalente ao total ingressado (CONSELHO NACIONAL DE JUSTIÇA, 2011).

\section{CONCLUSÃO}

Verifica-se, inicialmente, que existem vários métodos alternativos de solução de conflitos, o que pode ajudar o Judiciário a transpassar a crise vivida nos últimos anos com a explosão descomunal do número de demandas a ele postas.

Entende-se, contudo, que o grande problema atual está em auxiliar profissionais a compreenderem esses métodos e, principalmente, aplicá-los na prática.

Assim, sugerimos inicialmente uma ampliação da carga horária das disciplinas que envolvem mediação de conflitos (e suas demais vertentes alternativas) ou, mais eficazmente, a implementação de uma disciplina exclusiva para meios não adversariais de conflitos.

Sugerimos, ainda, que tal disciplina não se escoe tão somente no campo teórico, mas sim se utilizando de meios práticos e tentando, ao máximo, a utilização de material real 
(processos reais em tramite no Judiciário nacional) para que quando chegarem ao mercado de trabalho esses profissionais estejam preparados para evitar um explosivo número de demandas judiciais, levando as partes a uma solução interacionista e não judicial-impositiva

\begin{abstract}
Nowadays it is visible the huge amount of work at the Brazilian Judiciary, especially in causes that could be solved without the need of State intervention, the so called Alternative Dispute Resolution (ADR). At the same time there is the unprepared law force work to deal with the possibility of pacific resolution through agreement. This paper presents and explains the different alternative dispute resolution (ADR) in Brazilian law and also which approaches professors can use to prepare better law professionals.
\end{abstract}

Keywords: Conciliation. Mediation. Arbitration. Alternative. Dispute Resolution (ADR).

\title{
REFERÊNCIAS
}

AZEVEDO. Andre Gomma de. Teoria do conflito e os mecanismos autocompositivos. Técnicas de negociação e mediação. Procedimentos, posturas, condutas e mecanismos aptos a obter a solução conciliada dos conflitos. - Concurso da Magistratura: Noções gerais de Direito e Formação Humanística. 2 ed. São Paulo: Saraiva, 2012.

BORGES. Marina Soares Vital. Aprendendo a ensinar direito o Direito: Oficinas para o Direito: Uma contribuição de Vygostsky. Florianópolis: OAB/SC Editora, 2006.

Conselho Nacional de Justiça (CNJ). Conciliação. Disponível em: http:// www.cnj.jus.br/programas-de-a-a-z/acesso-a-justica/conciliacao. Acesso em: 23 de agosto de 2013.

Conselho Nacional de Justiça (CNJ). Justiça em Números: relatório 2011. Disponível em: http://www.cnj.jus.br/programas-de-a-a-z/eficienciamodernizacao-e-transparencia/pj-justica-em-numeros/relatorios Acesso em: 23 de agosto de 2013. 
DEOLINDO. Vanderlei. Medidas a serem adotadas pela AMB junto às instituições de ensino jurídico do país. Revista da Escola Nacional da Magistratura - ano VII. Brasília: Escola Nacional da Magistratura, 2012.

DIDIER JÚNIOR. Fredie. Curso de direito processual civil: introdução ao direito processual civil e processo de conhecimento. 14 ed. Salvador: JusPodivm. 2012.

DINAMARCO. Cândido Rangel. Instituições de Direito Processual Civil: vol. I. 4ed. São Paulo: Malheiros, 2004.

MASETTO. Marcos T. Docência Universitária: repensando a aula. Disponível: http://pt.scribd.com/doc/133993387/MASETTO-DocenciaUniversitaria-pdf. Acesso em 23 de agosto de 2013.

MEDINA. José Miguel Garcia. Processo Civil Moderno: procedimentos cautelares e especiais. 3 ed. São Paulo: RT, 2012.

MENDONÇA, Rafael. (Trans)modernidade e mediação de conflitos: pensando paradigmas, devires e seus laços com um método se solução de conflitos). Florianópolis: Editora Habitus, 2006.

WAMBIER. Luiz Rodrigues. Curso Avançado de Processo Civil: Teoria Geral do Processo e Processo de Conhecimento. 13 ed. São Paulo: RT, 2013.

WARAT. Luis Alberto. O ofício do mediador. Florianópolis: Editora Habitus, 2001. 